Available online on 15.07.2018 at http://jddtonline.info
Journal of Drug Delivery and Therapeutics
Open Access to Pharmaceutical and Medical Research
$\begin{gathered}\text { O 2011-18, publisher and licensee JDDT, This is an Open Access article which permits unrestricted non- } \\ \text { commercial use, provided the original work is properly cited }\end{gathered}$

Open $\odot$ Access

Research Article

\title{
KNOWLEDGE, ATTITUDE AND PRACTICES ON ANTIBIOTIC USE AND RESISTANCE AMONG DOCTORS IN B.P. KOIRALA INSTITUTE OF HEALTH SCIENCES
}

\author{
Sarraf Deependra Prasad*, Rai Dillisher, Rauniar Gajendra Prasad \\ Department of Clinical Pharmacology and Therapeutics, B.P. Koirala Institute of Health Sciences, Dharan, Nepal
}

\section{ABSTRACT}

Background: Assessment of knowledge, attitudes and practices (KAP) of antibiotic prescription among doctors may help in developing guidelines to improve antibiotics use and decrease resistance.

Aims and objectives: Our aim was to evaluate KAP regarding antibiotic use and its resistance among doctors.

Materials and Methods: A cross sectional, questionnaire based study was conducted among the doctors of B.P. Koirala Institute of Health Sciences, Dharan, Nepal between January-March 2016 and their KAP regarding antibiotic use and resistance was assessed by using a five point Likert scale. The data were analyzed by calculating percentage and frequency.

Results: Almost half of the doctors $(50.2 \%)$ used to prescribe antibiotics more than once daily. Nearly two thirds of the doctors $(65.3 \%)$ received antibiotic education at a formal lecture on ward rounds. Most of the doctors (87.4\%) agreed that antimicrobials are overused. One hundred thirty four doctors $(42.3 \%)$ agreed that patients' demands for antibiotics contribute to its overuse. Nearly two third doctors $(70.7 \%)$ believed that locally developed antimicrobial guidelines would be more useful. Most of the respondents $(89.9 \%)$ wanted more ongoing education on antibiotic use and its resistance.

Conclusions: Our study reveals that antibiotics are overused and patients' demand contributes to this. Locally developed antimicrobial guidelines would be more useful. More CME on antibiotic use and its resistance should be conducted to enhance the awareness among doctors.

Keywords: Antibiotics; Attitude; Antimicrobial drug resistance; Knowledge.

Article Info: Received 18 March, 2018; Review Completed 11 June 2018; Accepted 13 June 2018; Available online 15 July 2018

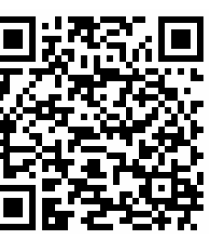

Cite this article as:

Sarraf DP, Rai D, Rauniar GP, Knowledge, attitude and practices on antibiotic use and resistance among doctors in B.P. Koirala institute of health sciences, Journal of Drug Delivery and Therapeutics. 2018; 8(4):170-175 DOI: http://dx.doi.org/10.22270/jddt.v8i4.1753

*Address for Correspondence:

Dr. Deependra Prasad Sarraf, Associate Professor, Department of Clinical Pharmacology and Therapeutics, B.P. Koirala Institute of Health Sciences, Dharan, Nepal

\section{INTRODUCTION}

Antimicrobial resistance (AMR) is one of the most serious public health issues. It results in increased hospital stay, costs, morbidity and mortality.,2 Overprescription, unnecessary prescription, incomplete treatment and inappropriate self-medication are common causes of AMR. ${ }^{3,4,5}$ A strategic global response is required to preserve current antimicrobial agents (AMA) and to reduce development of AMR. ${ }^{6,7}$ Appropriate antibiotic selection, dose and duration of treatment could prevent or even slow down the emergence of AMR. ${ }^{8}$ Changes in doctors' attitude ultimately affect the practice of antibiotic prescription. ${ }^{9}$ If the doctors are made aware of their prescribing practices, they will adopt the guideline. ${ }^{10}$. KAP studies can be used to analyze the prescribing practices of doctors. ${ }^{11}$

\section{Objectives:}

Our aim was to assess the KAP of doctors on antibiotic use and its resistance to understand what doctors know about antibiotics, how they acquire and maintain their knowledge up-to-date, how they prescribe it and what factors influence their prescription.

\section{MATERIALS AND METHODS}

A questionnaire based cross sectional descriptive study was conducted among doctors at B.P. Koirala Institute 
of Health Sciences (BPKIHS), a 763-beded university teaching hospital in Eastern Nepal between JanuaryMarch, 2016. The questionnaire developed by Sriniwasan et al was used with modifications with prior permission. ${ }^{9}$ The questionnaire consisted of 32 items including demographic information of the participants, questions on how frequently they prescribed antibiotics, how often they asked for and received input into antibiotics selections, how often and in what setting they received formal teaching about antibiotics, what sources of information they found useful for antibiotics education. It also consisted of 14 questions to assess their attitude about the problems of antibiotics resistance and its potential solutions. Ethical approval was taken from the Institutional Review Committee. Convenient sampling method was used. Written informed consent was taken from the participant. All data were coded and entered into MS Excel 2007 and analyzed with SPSS version 11.2 (SPSS Inc). A descriptive analysis was done by calculating frequency and percentage.

\section{RESULTS}

Total of 400 questionnaires were distributed and 317 were collected giving overall response rate of $79.2 \%$. Of the total doctors, $183(57.7 \%)$ were under the age of 30 years, $233(73.5 \%)$ were males, $286(90.2 \%)$ Nepalese doctors (Figure 1).
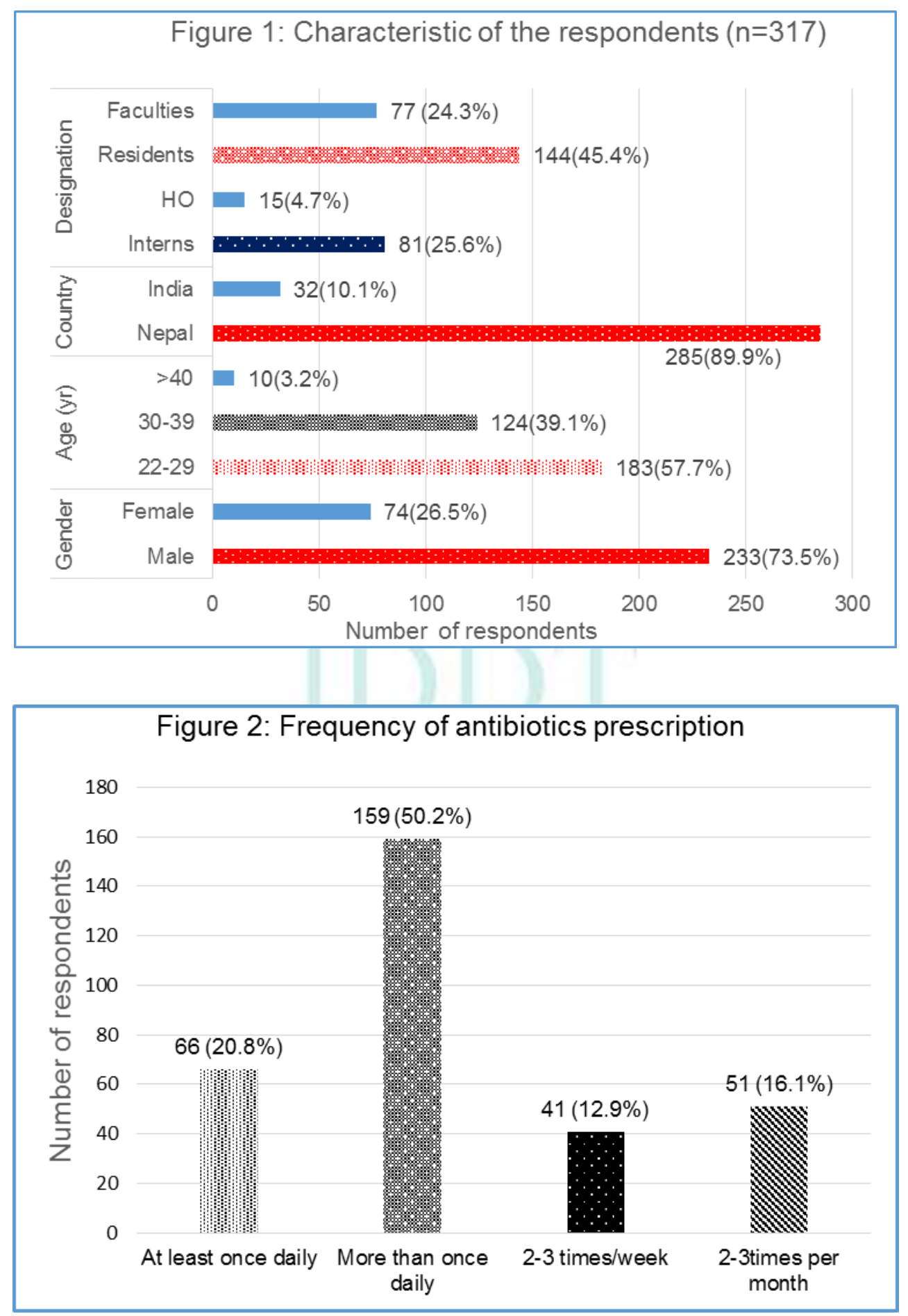
All respondents (100\%) agreed that strong knowledge of antibiotics was important to their career. Almost half of the respondents $(50.2 \%)$ used to prescribe antibiotics more than once daily (Figure 2). Pediatric doctors reported prescribing antibiotics more frequently than others, with $76.2 \%$ prescribing more than once daily (Table 1).

Nearly half of the doctors (49.5\%) used to seek input on their antibiotics selections from the seniors (Figure 3). More than two thirds doctors $(74.8 \%)$ agreed that sometimes their senior recommended different antibiotics they had chosen initially. Two hundred twenty seven doctors $(71.6 \%)$ felt that they were somewhat confident that they used antibiotics optimally (Figure 4).
Table 1: The departments prescribing antibiotics more than once daily

\begin{tabular}{|l|c|c|}
\hline Departments & $\begin{array}{c}\text { Number of } \\
\text { respondents } \\
(\%)\end{array}$ & $\begin{array}{c}\text { Total } \\
\text { respondents }\end{array}$ \\
\hline Pediatrics & $16(\mathbf{7 6 . 2})$ & 21 \\
\hline Ophthalmology & $9(69.2)$ & 13 \\
\hline $\begin{array}{l}\text { Obstetrics and } \\
\text { Gynecology }\end{array}$ & $24(64.9)$ & 37 \\
\hline Orthopedics & $10(62.5)$ & 16 \\
\hline Surgery & $16(61.5)$ & 26 \\
\hline Internal Medicine & $13(44.8)$ & 29 \\
\hline
\end{tabular}
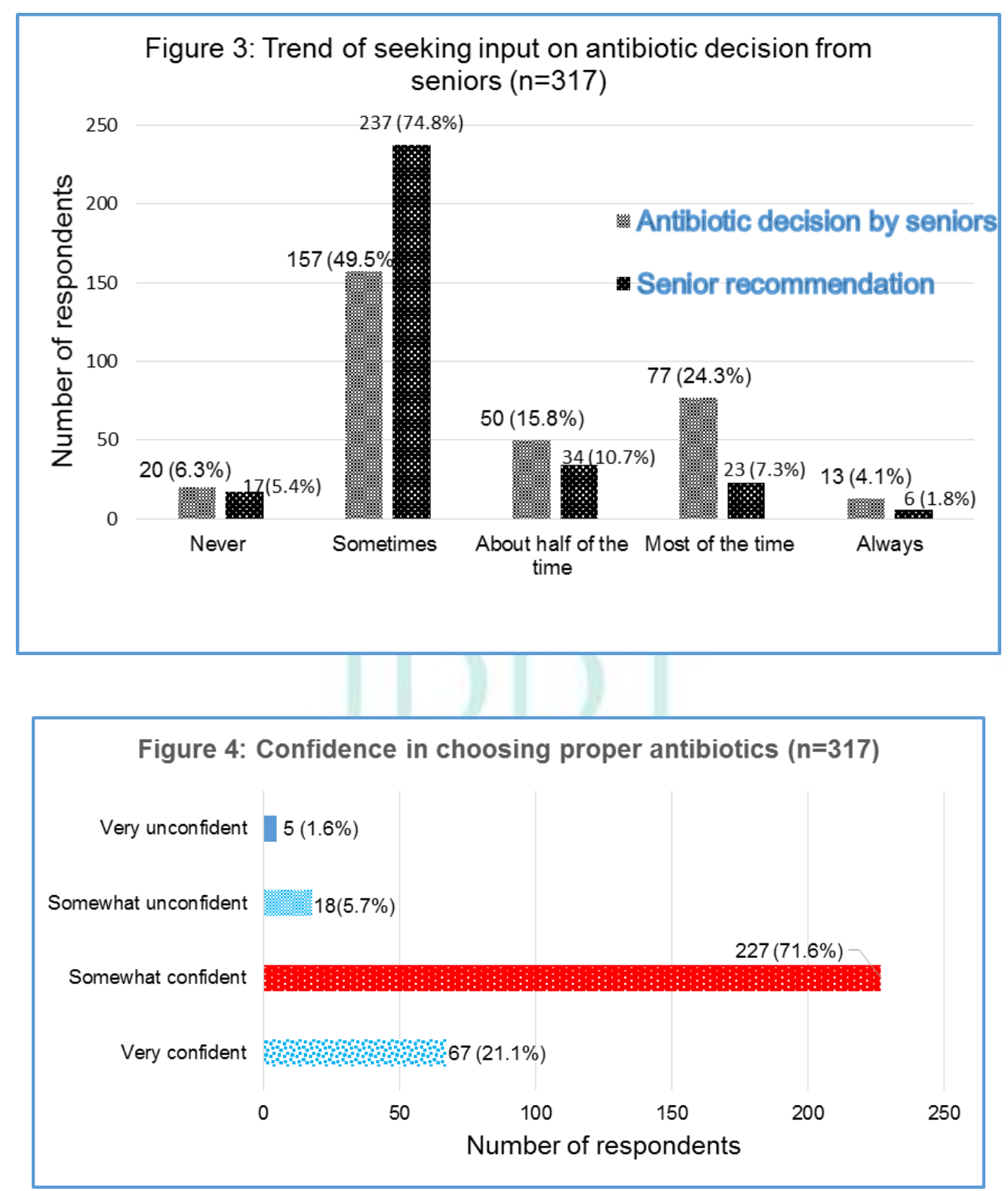

This confidence was highest among house officers $(80 \%)$ followed by interns $(76.5 \%)$, residents $(74.3 \%)$ and faculties $(59.7 \%)$. Forty five $(14.2 \%)$ doctors stated that they were not exposed to any formal education on antibiotics in the last 12 months. For those who reported exposure of some formal education, 207 (65.3\%) stated that they had received this education at a formal lecture on ward-rounds, 157 (49.5\%) during CME and 96 $(30.3 \%)$ at a pharmaceutical company-sponsored lecture (Figure 5). 


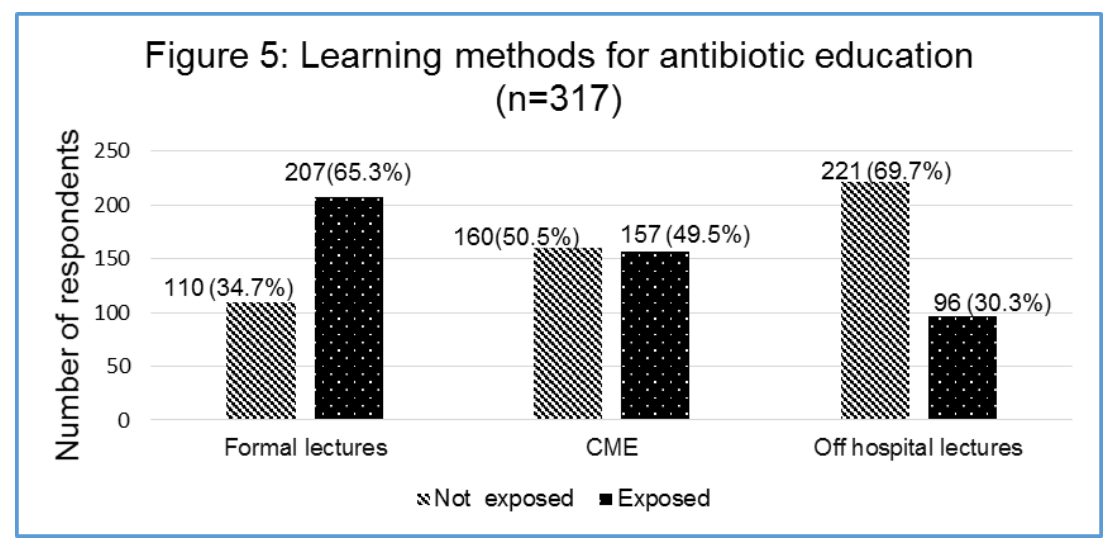

The usefulness of various sources of antibiotic continuing education and information is summarized in Figure 6.

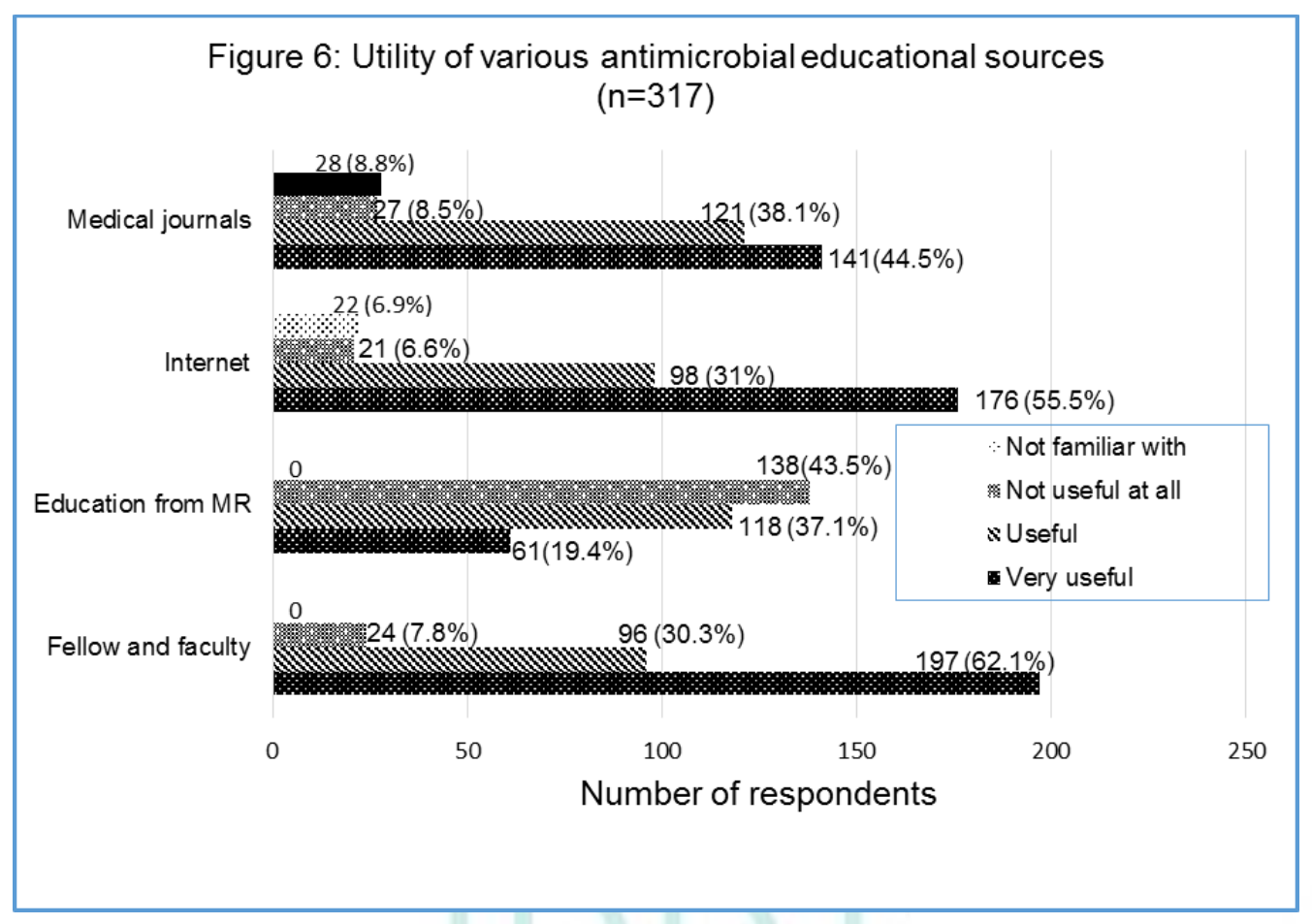

Overall fellow and faculty, internet and medical journals were rated as the most useful with pharmaceutical representatives being the least useful as a source of antibiotic knowledge. One hundred thirty five doctors
(42.6\%) mentioned name of internet site used for being up-to-date on antibiotics and its resistance pattern. Three most common visited internet sites were Medscape, Uptodate and Pubmed (Figure 7).

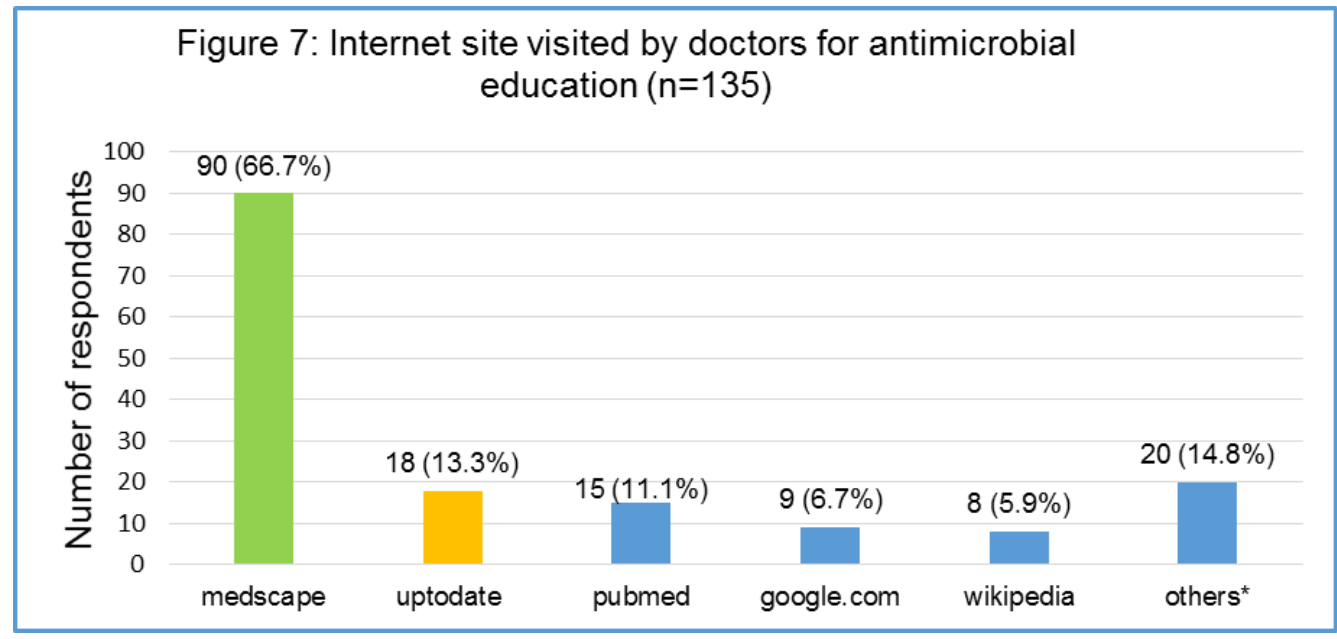

Others include drugs.com, webmed.com, medline.com, emedicine.com, cdc.gov, www.who.int/hinari/en/, skyscape.com. 
Most of the doctors $(93.4 \%)$ use a handheld device like Smartphone (Android phone or iPhone) for obtaining relevant antibiotic information. The doctors used the device most commonly for selecting appropriate drug for the patients (Figure 8). The attitude of the doctors on antibiotic use and its resistance is given in Table 2.

Table 2: Participants' attitudes on antibiotic use and its resistance $(n=317)$

\begin{tabular}{|l|c|c|c|}
\hline \multicolumn{1}{|c|}{ Attitudes } & Agree (\%) & $\begin{array}{c}\text { Neutral } \\
(\%)\end{array}$ & $\begin{array}{c}\text { Disagree } \\
(\%)\end{array}$ \\
\hline Antibiotics are overused in general. & $277(87.4)$ & $32(10.1)$ & $8(2.5)$ \\
\hline Antibiotics are overused at BPKIHS. & $177(55.8)$ & $107(33.8)$ & $33(10.4)$ \\
\hline $\begin{array}{l}\text { Hospitals in general face serious problems with antibiotic resistant } \\
\text { organisms. }\end{array}$ & $258(81.4)$ & $50(15.8)$ & $9(2.8)$ \\
\hline Antibiotic resistance does not present a significant problem at BPKIHS & $42(13.2)$ & $80(25.2)$ & $195(61.5)$ \\
\hline $\begin{array}{l}\text { Overall issues of bacterial resistance should be considered when prescribing } \\
\text { antibiotics for an individual patient. }\end{array}$ & $281(88.6)$ & $30(9.5)$ & $6(1.9)$ \\
\hline $\begin{array}{l}\text { Patient-demands for antibiotics contribute to antibiotic overuse for in- } \\
\text { patients }\end{array}$ & $134(42.3)$ & $68(21.4)$ & $115(36.3)$ \\
\hline $\begin{array}{l}\text { Better use of antibiotics will reduce problems with antibiotic resistant } \\
\text { organisms. }\end{array}$ & $281(88.6)$ & $29(9.1)$ & $7(2.2)$ \\
\hline $\begin{array}{l}\text { Locally developed guidelines for antibiotic treatment would be more useful } \\
\text { to me than national guidelines. }\end{array}$ & $224(70.7)$ & $68(21.5)$ & $25(7.8)$ \\
\hline $\begin{array}{l}\text { Antibiotic utilization/management programs are more of an obstacle than an } \\
\text { aid to good patient care. }\end{array}$ & $89(28.1)$ & $93(29.3)$ & $135(42.6)$ \\
\hline I get useful feedback on my antibiotic selections. & $127(40.1)$ & $150(47.3)$ & $40(12.6)$ \\
\hline I would like more feedback on my antibiotic selections. & $267(84.2)$ & $44(13.9)$ & $6(1.9)$ \\
\hline I would like more, ongoing education on antibiotics. & $285(89.9)$ & $28(8.8)$ & $4(1.3)$ \\
\hline $\begin{array}{l}\text { Interactions with pharmaceutical representatives do not influence my } \\
\text { antibiotic selections }\end{array}$ & $168(53)$ & $99(31.2)$ & $50(15.8)$ \\
\hline $\begin{array}{l}\text { Interactions with pharmaceutical representatives influence antibiotic } \\
\text { selections of other health care providers. }\end{array}$ & $143(45.1)$ & $128(40.4)$ & $46(14.5)$ \\
\hline
\end{tabular}

\section{DISCUSSION}

To our knowledge, this is the first study to focus the KAP on antibiotic use and its resistance among doctors in Eastern Nepal. We have included all levels of doctors from interns to professor and from all the clinical departments as well as dental surgeons. Our study had provided useful and in-depth information about the KAP on antibiotic use and its resistance. The overall response rate of $79.2 \%$ was similar to the other surveys. ${ }^{12,13}$ Our study reflected that doctors in Pediatrics and Ophthalmology departments were the most likely of the respondent group to report prescribing antibiotics more than once a daily compared to other departments. This finding was not in consistent with that of Srinivasan et al in which doctors of Emergency department prescribed antibiotics more than once daily. ${ }^{9}$ Therefore, the clinical departments other than Internal Medicine are equally important if any antibiotic guidelines is going to be prepared and implemented. Our study found that almost half doctors used to take help from their seniors on their antibiotic decisions which signified good communication between junior and seniors. Similar findings was also reported by Srinivasan et al in their report. ${ }^{9}$ Our study showed that the doctors at lower level interacted well with that of higher level about antibiotic selection; this interdependency may be important in planning guidelines on antibiotic use. The interventions that focus on upper-level doctors are likely to be much more effective.
Our study also indicated that most of the doctors were confident in choosing the correct antibiotic. The confidence was highest among house officers. A higher level of confidence was reported in other studies. ${ }^{[14]}$ Srinavasan et al found that only $21 \%$ doctors were confident in their antibiotic selection. ${ }^{9}$ Exposure to continued medical education, proper guidance from the seniors and periodic dissemination of hospital antibiogram may help them in increasing their confidence in antibiotic selection and prescription. Our study also revealed that doctors were well exposed to continued medical education on antibiotic use and its resistance pattern. It may help them to adopt the guidelines and recommendations. Nearly half of the doctors disagreed that knowledge provided by pharmaceutical representatives were useful for antibiotic prescription. This finding is different from other study. ${ }^{14}$ Policy makers should advocate and arrange for more frequent educational activities and workshops to train doctors periodically on antibiotic prescription and it resistance in order to keep them uptodate. Almost half of the doctors agreed that they are using antibiotics in excess at their own hospital. These findings are in consistent with other studies. ${ }^{12,14}$ Most of the doctors agreed that hospital would face serious problem of antibiotic resistant organisms. These results were in consistent with others' report. ${ }^{12}$

Most of doctors believed that overall issues of resistance should be considered when prescribing therapy for an individual patient and this finding is consistent with 
others'. ${ }^{9}$ Our study also showed that patient demands for antibiotics also contribute to antibiotic overuse. The use of antibiotics should be evidence based. Therefore, the public should also be well educated regarding proper use of antibiotics. Most of the doctors believed that better antibiotic use would help address the issue of resistance. In a study done by Webster et al, only $66 \%$ doctors had such believe. ${ }^{12}$ In another study done by Srinivasan et al, 97\% doctors believed that proper antibiotic use may decrease AMR. ${ }^{9}$

Nearly half of the doctors dis-agreed that antibiotic management programs program were actually more of an obstacle than an aid to good patient care. This finding was opposite to that of Srinivasan et al in which $82 \%$ doctors believed in that. ${ }^{9}$ More than two third of the doctors agreed that locally developed guidelines would be more useful than the national ones and similar findings were also reported by Srinivasan et al. ${ }^{9}$ Therefore local antibiotic guidelines should be prepared and implemented. More ongoing education on antibiotics was demanded by $89.9 \%$ doctors. Periodic educational program on antibiotics should be entertained to make them more aware. Almost half of the doctors received very little feedback about their antibiotic prescription habits and $84.2 \%$ demanded for more feedback. This was different from other report in which only $67 \%$ respondents demanded more feedback. ${ }^{9}$ Appropriate feedback on antibiotic prescribing may help the prescribers to change their prescribing habits and adopt new guidelines. Our study also revealed that the doctors had different view on effect of interactions with

\section{REFERENCES}

1. Michael CA, Dominey-Howes D, Labbate M. The antimicrobial resistance crisis: causes, consequences, and management. Front Public Health. 2014; 16(2):145.

2. Spellberg B, Guidos R, Gilber D, Bradley J, Boucher HW, Scheld WM et al. The epidemic of antibiotic-resistant infections: A call to action for the medical community from the Infectious Diseases Society of America. Clin Infect Dis. 2008; 46:155-164.

3. Antimicrobial resistance-global report on surveillance. World Health Organization, 2014, Geneva [cited 2015 October 15]. Available from: http://www.who.int/drugresistance/documents/surveillancere port/en/

4. Phelps CE. Bug/drug resistance. Med Care. 1988; 27(2):194203.

5. Antibiotic resistance threats in the United States. CDC, 2013, USA [cited 2015 October 15]. Available from: http://www.cdc.gov/drugresistance/pdf/ar-threats-2013508.pdf

6. Holmes AH, Sharland M. The Chennai Declaration: India's landmark national commitment to antibiotic stewardship demonstrates that 'truth alone triumphs'. J Antimicrob Chemother. 2013; 50:71-3.

7. Hayashi Y, Davis L, Paterson DL. Why can't I prescribe that antibiotic? The role of antimicrobial stewardship programmes in modern medicine. Intern Med J. 2009; 39:636-8.

8. Shlaes DM, Gerding DN, John JF, Craig WA, Bornstein DL, Duncan RA et al. SHEA position paper: Society for Healthcare Epidemiology of America and Infectious Diseases pharmaceutical representatives affect their antibiotic selections. Almost half of the doctors agreed that these interactions did not affect their own antibiotic selection. Ideally the antibiotic selection must be evidence based; it should not be influenced by such interactions.

Our studies have some limitations. The responses might have been influenced by recall bias. The doctors often do not practice what they tell. Their attitude might be different when the investigator is away. The result may not be generalized to whole country. Qualitative study should be conducted to validate the results in larger population.

\section{CONCLUSIONS}

Our study provide a better understanding and a baseline data of what doctors know about antibiotic and AMR that can be used to prepare local and national guidelines. Most of the doctors believed that better use of antibiotics would help to reduce the problem of AMR. There was also a general desire among doctors for more educational programs and more feedback on their antibiotic decisions. Formulation and dissemination of local antibiotic guidelines and educational conferences, seminars and formal lectures on antibiotic use and its resistance pattern may help in voluntary change in prescribing behavior of the doctors.

Acknowledgments: We would like to thank all doctors who participated in the study and Dr. Arjun Srinivasan.

Conflicts of Interest: None
Society of America Joint Committee on the prevention of antimicrobial resistance: Guidelines for the prevention of antimicrobial resistance in hospitals. Infection Control and Hosp Epidemiol. 1997; 18:275-91.

9. Srinivasan A, Song X, Richards A, Sinkowitz-Cochran R, Cardo D, Rand C. A survey of knowledge, attitudes and beliefs of house staff physicians from various specialties concerning antimicrobial use and resistance. Arch Intern Med. 2004; 164:1451-56.

10. Cabana MD, Rand CS, Powe NR et al. Why don't physicians follow clinical practice guidelines? a framework for improvement. JAMA. 1999; 282:1458-65.

11. Okeke I. Poverty and root causes of resistance in developing countries. In: Sosa A, Byarugaba D, Amabile-Cuevas C, Hsueh P, Kariuki $\mathrm{S}$ et al., eds. Antimicrobial resistance in developing countries. First edition, New York; Springer; 2010; p. 27-36.

12. Wester CW, Durairaj L, Evans AT, Schwartz DN, Husain S, Martinez E. Antibiotic resistance: a survey of physician perceptions. Arch Intern Med. 2002; 162:2210-16.

13. Katuala Y, Batoko B, Alworonga JP, Devlieger H, et al. Antibiotic Prescribing in DR Congo: A Knowledge, Attitude and Practice Survey among Medical Doctors and Students. PLoS One. 2013; 8(2):e55495.

14. Thriemer K, Katuala Y, Batoko B, Alworonga JP, Devlieger $\mathrm{H}$, Van Geet $\mathrm{C}$ et al. Antibiotic prescribing in DR Congo: a knowledge, attitude and practice survey among medical doctors and students. PLoS One. 2013; 8(2):e55495. 